Artigo de Divulgação 


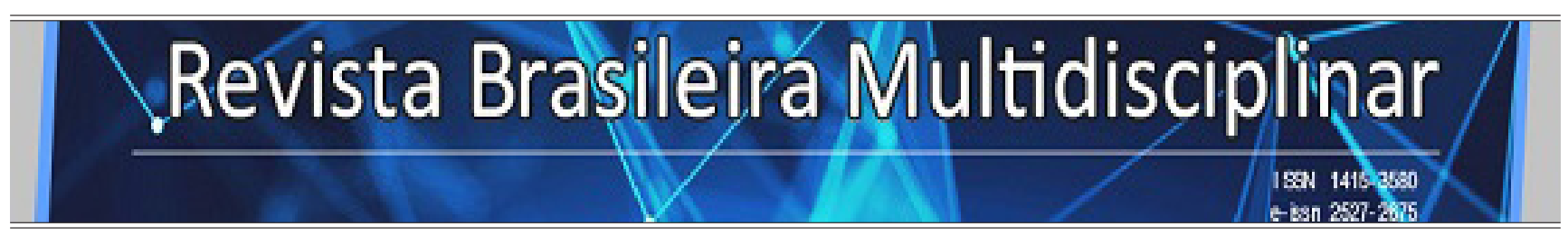

http://revistarebram.com/index.php/revistauniara

\section{ANÁlise da PROdução CIENTÍfica de brasileiros ACERCA da CERTIFicaÇão FLORESTAL}

Gabriel de Mello Freire*; Jaqueline de Paula Heimann*; Letícia Helena Ribeiro da Cunha***.

* Engenheiro Florestal, Mestrando em Economia, Administração e Política Florestal- Universidade Federal do Paraná UFPR.

** Engenheira Florestal, Mestre Doutoranda em Economia, Administração e Política Florestal Universidade Federal do Paraná UFPR.

${ }^{* * *}$ Engenheiro Florestal, Mestranda em Economia, Administração e Política Florestal, Universidade Federal do Paraná UFPR.

*Autor para correspondência e-mail: gabrieldmellof@hotmail.com

\section{Palavras-chave}

Floresta Tropical

FSC

Produção Científica

Selos Verdes

Sustentabilidade

\section{KEYWORDS}

Tropical Forest

FSC

Scientific Production

Green Stamps

Sustainability
Resumo: Esta pesquisa objetivou levantar dados bibliométricos e de conteúdo sobre artigos publicados que estejam voltados para a certificação florestal no Brasil. Buscou-se dar prioridade a autores brasileiros, mesmo que tenham publicações internacionais, realizando a busca na base de dados da Scopus. Frente a isso, foram registrados 67 artigos relacionados ao tema certificação florestal "forest certification", nas áreas de Ciências Sociais, Ciências Agrícolas e Biológicas, e Ciência Ambiental, nos quais foram analisados por meio do software VOSViewer ${ }^{\oplus}$. A análise bibliométrica identificou artigos dos últimos vinte e três anos, bem como os principais autores, instituições, periódicos com mais citações, artigos mais citados, processar as redes de coautoria e cocitação. Elaborados os clusters para identificar as temáticas abordadas, os resultados mostraram uma baixa interação entre autores muito distantes em questão de instituições e diferença temporal, porém uma forte contribuição ao se tratar de autores que pertencem a mesma filiação. O estudo revelou que os autores brasileiros se concentram em uma abordagem voltada para o setor industrial e a preocupação com o impacto ambiental, revelando a necessidade de explorar a questão socioambiental.

\begin{abstract}
ANALYSIS OF BRAZILLIAN SCIENTIFIC PRODUCTION ABOUT FOREST CERTIFICATIONS
This research aimed at raising bibliometric data and content about published articles focusing on forest certification in Brazil. Priority was sought for Brazilian authors, even if they publish internationally, performing a search in the Scopus database. Therefore, 67 articles related to the theme forest certification "forest certification" registered, in the areas of Social Sciences, Agricultural and Biological Sciences and Environmental Science, were analyzed using VOSViewer ${ }^{\oplus}$ software. A bibliometric analysis identified articles from the last twenty-three years, as well as the main authors, institutions, journals with the most citations, most cited articles, processing as co-authoring and cociting networks. After elaborating the clusters to identify the addressed themes, the results showed a low interaction between very distant authors in questions of institutions and temporal differences, but a strong contribution from authors who belong to the same affiliation. The study revealed that Brazilian authors were centered on an approach focused on the industrial sector and concerned with environmental impact, revealing the need to explore the social and environmental issue.
\end{abstract}




\section{INTRODUÇÃo}

A construção do conhecimento conta com o desenvolvimento da produção científica, uma vez que inúmeras pesquisas de diversas áreas são distribuídas à sociedade por meio de informações. Divulgar essas informações por canais diretos e indiretos é fundamental para a comunicação social e científica, e tendo em vista que estas produções vêm crescendo ao longo dos anos, torna-se ponto positivo e de interesse para estudos (SILVA, et al., 2011; TAVEIRA et al., 2013). Segundo Tasca et al. (2010) citado por Lacerda et al. (2012), a produção científica se inicia a partir de uma problemática que motiva o pesquisador a procurar por respostas dentro daquele tema que se encontram em outras produções científicas já publicadas.

No caso da certificação florestal, a crescente preocupação do setor do agronegócio e do setor de base florestal deu-se por conta do aspecto ambiental nas relações de comércio, pois a sociedade ao longo do tempo passou a incorporar questões ambientais nas decisões de consumo, refletindo na adequação de muitas empresas para atenderem esse tipo de mercado específico sem perder espaço (PAIVA et al., 2015). Jacovine et al. (2006) citam Silva (2003) alegando que a certificação florestal passou a ser adotado pelas empresas como forma de provarem produzir utilizando os recursos naturais de forma ambientalmente correta e socialmente benéfica.

A realização de estudos sobre a certificação florestal têm sido elemento forte no auxílio para entendimento desse processo na produção do setor florestal, principalmente. Nesse contexto, torna-se interessante pesquisar a situação atual do campo de conhecimento acerca da certificação florestal no Brasil, considerando métodos específicos da bibliometria, como por exemplo a análise de redes (FREITAS; PAIVA, 2018).

Conforme ainda apresentado por Freitas e Paiva (2018), a análise de redes é o método que permite apontar similaridades entre estudos sobre o mesmo tema ou área, e a ferramenta utilizada para tal procedimento é um software chamado VOSViewer ${ }^{\oplus}$, referente à Visualization of Similiarities (VOS) (VAN ECK; WALTMAN, 2010).

Este estudo objetivou analisar a produção científica sobre a certificação florestal feita por brasileiros e publicadas nas áreas de Ciências Biológicas e Agrícolas, Ciência Ambiental e Ciências Sociais, bem como a análise de conteúdo dos artigos encontrados. A base de dados utilizada para esta pesquisa bibliométrica foi a base de dados da Scopus, que segundo Goulart e Carvalho (2008) citados por Freitas e Paiva (2018), possui extenso acervo de publicações internacionais que reforçam a produção científica de diversos campos de conhecimento. A presente pesquisa segue estruturada em cinco partes.

Após a introdução e objetivo dessa pesquisa, a segunda parte aborda a revisão de literatura sobre os estudos de certificação florestal e análise de redes. A terceira parte comtempla os procedimentos metodológicos adotados aqui, seguidos da quarta parte que trata dos resultados encontrados e discussão dos mesmos. Por fim, vem as considerações finais e recomendações.

\section{REVISÃo Da Literatura}

\section{CONTEXTUALIZAÇÃo da CERTIFICAÇÃo FLORESTAL}

Devido à utilização desenfreada dos recursos naturais em meados dos anos 80 e 90, num contexto histórico, o surgimento da certificação florestal em 1993 veio como forma de proteger o esgotamento de tais recursos florestais por serem explorados erroneamente. A certificação florestal em si é tida como um mecanismo mercadológico que permite a rotulagem destes produtos da floresta para garantirem que provém de um manejo sustentável (MOURA, 2016). Para Basso et al. (2012), o empreendedor ao adquirir a certificação florestal, está buscando informar ao consumidor que determinados padrões de desempenho estão sendo seguidos e monitorados para que utilizem corretamente áreas florestais.

O setor florestal brasileiro nos dias de hoje desempenha importante papel também na preservação dos recursos naturais. Estudos sobre certificação florestal (SPATHELF et al., 2004; JACOVINE et al., 2006; OLIVEIRA et al., 2011; PAIVA et al., 2015) conforme citados por Leite et al. (2018), buscaram analisar a 
eficiência da certificação, bem como o processo da certificação florestal em empreendimentos brasileiros.

Segundo Pinto e McDermott (2013), a fundação de um padrão de certificação florestal, o FSC, surgiu na Alemanha diante de um grupo de gestores e ambientalistas que visavam o manejo de florestas de modo sustentável. O padrão FSC é abreviação para Forest Stewardship Council (traduzido como Conselho de Manejo Florestal). A adesão é prática voluntária e sem fins lucrativos, representando aspectos sociais, econômicos e ambientais. Carneiro (2011) alega que a certificação florestal no Brasil pelo padrão FSC deu-se de forma satisfatória em termos de crescimento, como resultado da união entre ONGs, um pequeno grupo de empresários e integrantes de órgãos ambientais federais e estaduais.

Apesar da certificação florestal pelo FSC ser bastante conhecida ou até mesmo muito comum, existe outros tipos de certificação florestal como o PEFC (Programme for the Endorsement of Forest Certification Schemes) e o Sistema Brasileiro de Certificação Florestal, CERFLOR. O PEFC fundado em 1999, também possui caráter voluntário e surgiu com o propósito de reconhecimento dos diferentes sistemas de certificação dos países europeus. Quanto ao CERFLOR, este foi desenvolvido pela ABNT em parceria com o Inmetro, pretendendo avaliar o manejo das florestas plantadas e nativas nacionais (CARNEIRO, 2011).

Moura (2016) apresenta dados dos sistemas de certificação onde sistemas de certificação FSC e PEFC até o ano de 2015 possuíam junto, um total de 459 milhões de hectares certificados em todo o mundo, enquanto que no Brasil, a área certificada pelos sistemas FSC e CERFLOR totalizavam 8,9 milhões, abrangendo 128 propriedades.

Tratando do crescimento de estudos acerca da certificação florestal, e pelo padrão FSC mais fortemente, Rafael et al. (2018) ressalvam que o importante agora é não mais pensar na certificação florestal do ponto de vista de como ela desempenha seu papel, mas sim começarem a ver o "como", pois muita das dificuldades existentes está em como promover a certificação e explicar a contribuição dela para um mercado florestal sustentável. Os autores dizem ainda que no Brasil, ou mesmo em qualquer país, o grande desafio se mostra na disseminação das informações e nas barreiras criadas por conta disso.

Diante das vantagens competitivas que a certificação florestal proporciona para os empreendimentos do setor base, a busca por certificar tem sido a estratégia de negócio viável para atingir nichos específicos de mercado (PAIVA et al., 2015).

\section{O ESTUDO BIBLIOMÉTRICO}

Segundo Oliveira et al. (2013) citado por Santos (2015), a bibliometria ou estudo bibliométrico, é uma ferramenta para transmissão de conhecimento sobre o estágio de publicações ou pesquisas sobre determinada área de conhecimento. O pensamento de Moraes (2013) também citado pelo autor afirma a análise das produções científicas como um recurso capaz de sustentar o conhecimento ao longo do tempo.

A sustentação de tal conhecimento por meio do monitoramento da produção científica é uma atividade que contribui significativamente para a composição da produtividade dos pesquisadores ou instituições (SANTOS, 2003), mas não se trata de uma atividade simples pelo fato de envolver formulação de técnicas e de recursos habilitados (SILVA et al., 2012). Para avaliação e monitoramento das produções, faz-se uso dos meta-dados (título, nome do autor, palavras-chave, etc.) que possibilitam realizar a análise de redes de autoria, coautoria, cocitação, entre outras (FREITAS; PAIVA, 2018).

Freitas e Paiva (2018) citando outros autores (BORDIN et al., 2014; PEREIRA et al., 2015) mostram o ponto de vista destes de que os resultados obtidos com redes de coautoria, indicador na análise de redes, são fundamentais para expressar a colaboração de pesquisadores diante da comunidade e os autores que mais colaboram, bem como a análise de citações que segundo Gracio et al. (2009) também citados por Freitas e Paiva (2018), indica o impacto que dos pesquisadores naquela área específica.

Entende-se o papel relevante da análise de produção científica de um país, tendo em vista que os indicadores bibliométricos retratam o comportamento de uma determinada área de conhecimento sobre 
pesquisas acerca do tema. Diversas são as áreas de estudos sobre bibliometria no Brasil, conforme Araújo \& Alvarenga (2011) citam autores que desenvolvem esse tipo de levantamento (VANZ, 2003; MACHADO; PINTO, 2005; MACHADO, 2007).

Investigar os estudos feitos no Brasil sobre certificação florestal mostra diferentes trabalhos voltados para a implantação desse mecanismo. À conta disso, este estudo busca contribuir por meio da busca por produção científica acerca da certificação florestal com o campo de conhecimento sobre o tema, mediante análise de redes de coautoria, periódicos, temáticas recorrentes e outras variáveis que se relacionam com a produção de conhecimento científico.

\section{Procedimentos Metodológicos}

O presente trabalho trata de um estudo baseado em análise de redes, com o objetivo de mapear a produtividade científica acerca da certificação florestal e a análise de conteúdo dos documentos. Para realizar o levantamento desta produção científica nas áreas de Ciências Agrícolas e Biológicas, Ciências Ambientais e Sociais, a base de dados da Scopus foi utilizada por ser considerada diante de autores como Freitas \& Paiva, 2018, a maior fonte de dados contendo publicações de áreas como ciências sociais, humanas, medicina, tecnologia, entre outras. Quanto à técnica qualitativa, esta foi utilizada para análise do conteúdo a nível de detalhamento, por meio da revisão dos artigos nos periódicos com mais publicações acerca do tema.

A pesquisa na base de dados da Scopus considerou os artigos publicados sobre "certificação florestal" até o dia 30 de setembro de 2019. Os critérios estipulados para a busca podem ser observados na Figura 1.

Figura 1 - Delineamento para a busca no banco de dados da Scopus.

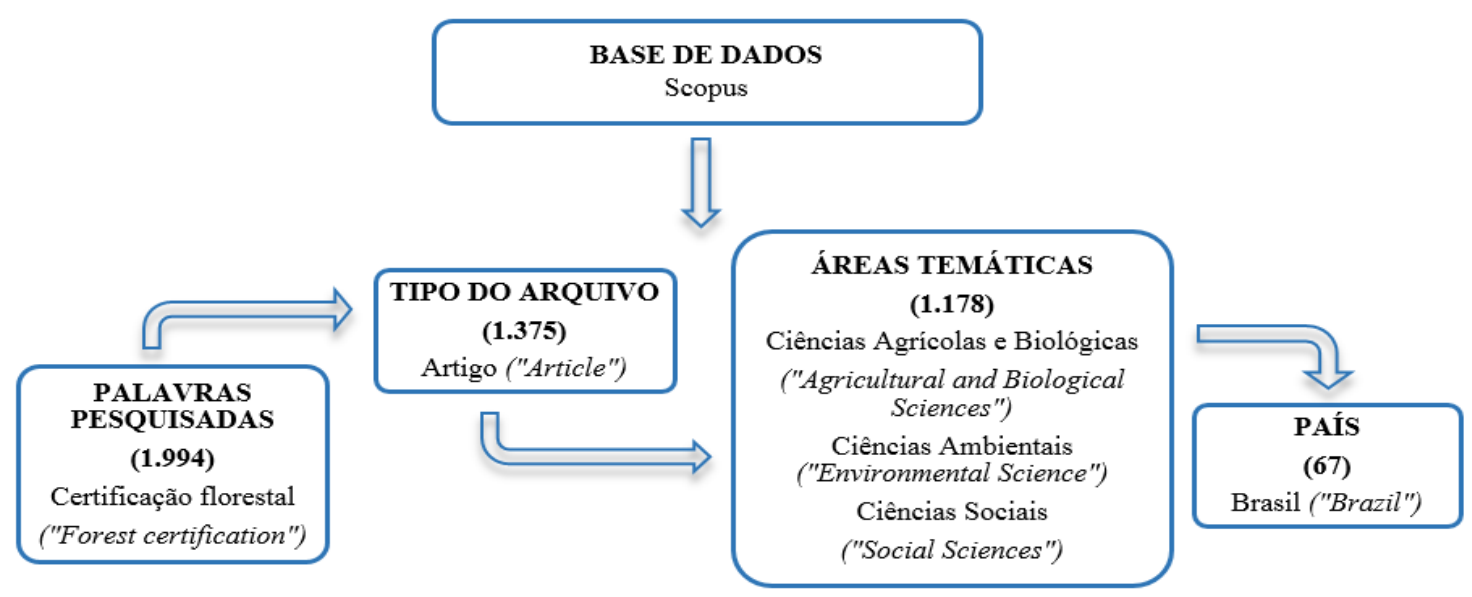

Fonte: Elaborado pelos autores.

Por meio das palavras pesquisadas, os termos "Certificação Florestal” ou "Forest Certification" foram utilizados para os tópicos "título", "resumo" e "palavras-chave". Seguido disso, os critérios definidos foram o tipo de arquivo, considerando somente Artigo ( "Article") nessa categoria de publicações, e depois a área das publicações, sendo elas "Ciências Agrícolas e Biológicas", "Ciências Ambientais" e "Ciências Sociais". Por fim, a delimitação do país de publicações foi "Brasil”, a fim de considerar ao menos um autor do artigo sendo brasileiro. O número total encontrado após aplicado o filtro de busca foi de 67 documentos.

Assim como feito ainda por Freitas e Paiva (2018), a análise dos dados por meio da análise de redes possibilitou: redes de coautoria, redes de cocitação, acoplamento bibliográfico, co-ocorrências de palavras- 
chave, autores mais frequentes, periódicos com mais publicações, bem como o crescimento de publicações ao longo dos anos, frequência das palavras em vários textos, número de citações, e instituições dos autores.

Proposto por Van Eck e Waltman (2010), o processamento para mapeamento das redes ocorreu por meio do software chamado VOSViewer ${ }^{\circledast}$ em sua versão 1.6.13, e também no Excel para tabulação dos dados descritivos como crescimento da publicação ao longo dos anos, frequência de autores, instituições e região.

\section{RESULTADOS E DISCUSSÃO}

\section{ANÁlise TEMPORAL dA PRODUÇão CIENTÍfica}

Ao que se trata da análise temporal das publicações feitas por brasileiros acerca da certificação florestal, o artigo mais antigo encontrado na base de dados está datado em 1996, com o título "Biological challenges for certification of tropical timber" de Putz e Viana (1996), em que alegavam haver necessidade da participação dos biólogos especialistas em espécies tropicais na elaboração dos critérios de certificação para espécies tropicais. Para os autores, a investigação das consequências ecológicas e silviculturais dos diferentes procedimentos seriam indicadores válidos para um bom manejo florestal.

Com base no Gráfico 1, observa-se um aumento nas produções sobre o tema por brasileiros ao longo dos anos. O crescimento significativo das publicações ocorre realmente a partir do ano de 2011, quando ao menos sete documentos foram publicados. A partir de então, anos como 2015, 2018 e 2019 tiveram consideráveis 9, 7 e 7 documentos publicados respectivamente, comparados aos demais anos da linha do tempo. Diante das 67 publicações encontradas, nota-se uma constante oscilação entre as publicações.

Gráfico 1 - Crescimento das publicações de brasileiros sobre certificação florestal.

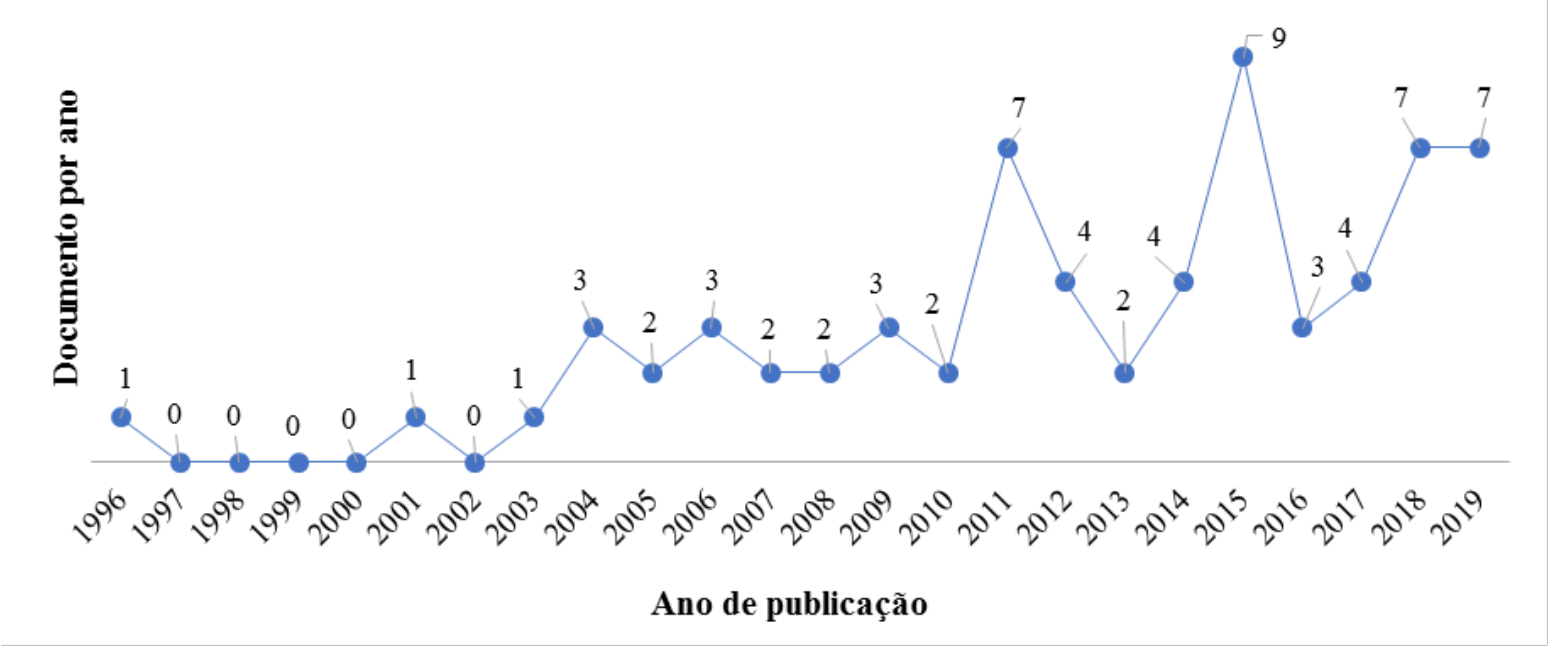

Fonte: Dados da pesquisa (2019).

Apenas a título de comparação e para agregar nesta pesquisa, foi possível notar no banco de dados da Scopus um total de 1.997 documentos sobre certificação florestal, considerando os países que já realizaram estudos sobre o tema. Isso mostra que os primeiros trabalhos acerca do assunto em nível internacional foram de 1974 com o artigo "Conference of Representatives of Local Medical Committees (1974), sem a identificação dos autores.

Dos artigos investigados, observou-se que apenas $49 \%$ retratavam da certificação florestal propriamente dita, voltada para os princípios e critérios do padrão FSC de certificação florestal, sendo o documento mais antigo do ano de 2001, com título "Plantation certification and genetic engineering: FSC's ban on research is counterproductive" dos autores Strauss et al. (2001) e publicado no Journal of Forestry. 


\section{Produtividade POR AUTOR E REDES DE COAUTORIA}

No Gráfico 2 observam-se os principais autores, aqueles com mais artigos publicados sobre certificação florestal nas áreas de Ciências Agrícolas e Biológicas, Ciências Ambientais e Ciências Sociais da base de dados da Scopus. Frente a isso, apenas dois autores, o professor Ricardo Ribeiro Alves da Universidade Federal do Pampa e o professor Laércio Antônio Gonçalves Jacovine da Universidade Federal de Viçosa apresentam expressivo número de artigos publicados, sendo 10 artigos cada um deles.

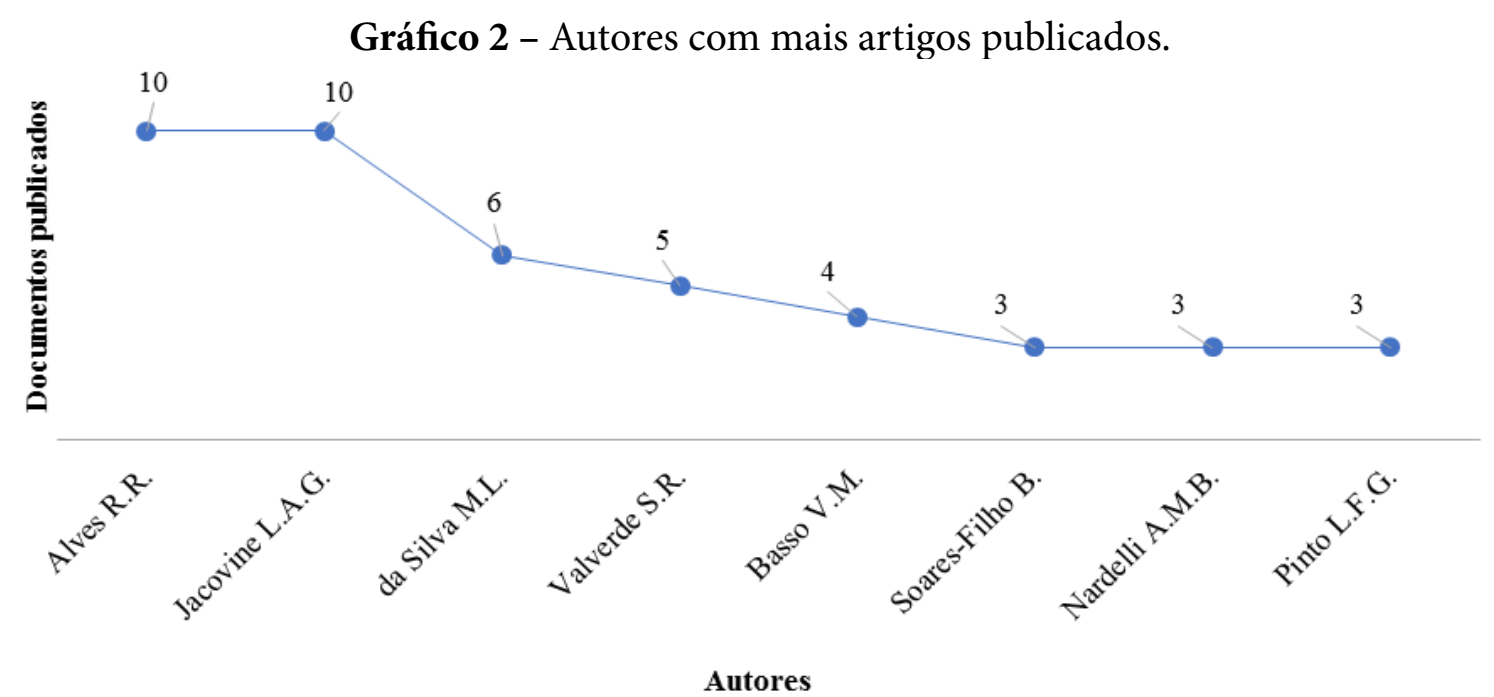

Fonte: Dados da pesquisa (2019).

O professor Laércio Antônio Gonçalves Jacovine é considerado referência quando o assunto é certificação florestal devido ao grande número de participações e autoria em trabalhos sobre o tema. Graduado, Mestre e Doutor pela Universidade Federal de Viçosa, onde também é professor, trabalha com ênfase na área de Economia Ambiental, atuando com créditos e sequestro de carbono, desenvolvimento sustentável, gestão ambiental e certificação florestal.

O professor Ricardo Ribeiro Alves, tem graduação em Administração e mestrado e doutorado em Ciência Florestal também pela Universidade Federal de Viçosa. O pós-doutorado em Marketing Ambiental pela Universidad de Zaragoza, na Espanha. Sua atuação principal é na área de sustentabilidade empresarial, com enfoque voltado ao comportamento do consumidor, mercado verde, consumo consciente, estratégias e vantagens competitivas, selos verdes e certificações de gestão e florestal.

Um ponto interessante notado em relação aos dois professores citados acima, Jacovine e Alves, é que, analisando os artigos publicados em que ambos participam, um está bastante presente como coautor do outro.

Observado isso, as redes de coautoria possibilitam identificar uma gama de produções científicas que são realizadas de forma conjunta por um grupo de pesquisadores (MAIA; CAREGNATO, 2008). As coautorias reforçam o fato de que os autores compartilham conhecimento, conteúdo, participando na construção do conhecimento científico e assumindo responsabilidade pelos trabalhos feitos. Nas redes de coautoria cada autor é representado por um ponto (ou nó), e a ligação entre nós representa ao menos um artigo publicado em conjunto entre os respectivos autores destacados nas redes de coautoria (MENA-CHALCO et al., 2012).

Freitas e Paiva (2018) alegam que quanto maior a frequência de documentos produzidos por um conjunto de autores, a ligação de forças entre os nós é maior. Para Sampaio et al. (2015), cada cor diferente se refere a um grupo com considerável número de pesquisadores, e os nós de tamanhos maiores fazem 
parte de um mesmo grupo. Os autores ainda alegam que quando há uma estrutura dessa maneira, com clusters ou grupos sem ligações, é porque por mais que o tema tratado seja o mesmo, os participantes dos grupos pertencem a diferentes áreas e têm pouca interação entre si.

A amostra contou com 225 autores no total, podendo ser identificados 45 clusters, onde os tamanhos dos círculos (nós) se referem aos documentos publicados, conforme apresenta a Figura 2.

Figura 2 - Redes de coautoria.

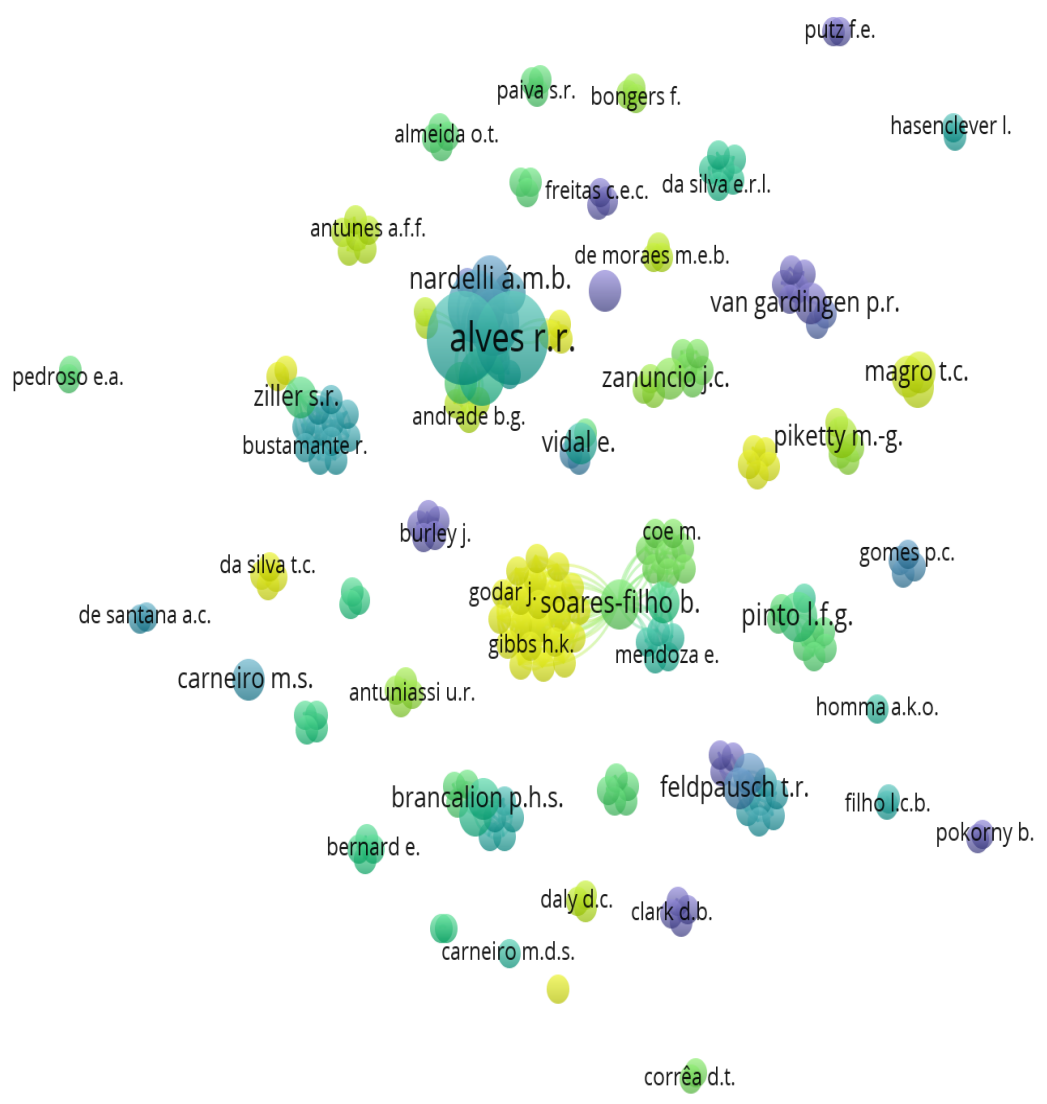

Fonte: Dados da pesquisa (2019).

O cluster com maior número de link está formado por 21 autores, e o tamanho do círculo mostra que Alves R. R. com 10 documentos tem maior número de documentos publicados juntamente com Jacovine L. A. G. (10 documentos), seguidos por Da Silva M. L. com 6. Notou-se que houve uma variação muito grande de clusters contendo de 1 a 9 autores, o que pode indicar dispersão da produção científica acerca do tema (FREITAS; PAIVA, 2018).

A composição da coautoria mostrou a quantidade de autores por artigos, apresentando assim a maioria deles com 3 autores (15 artigos), 4 autores (13 artigos) e 2 autores (11 artigos). Os de menor ocorrência foram artigos com 8, 10, 12 e 22 autores participantes na produção. Em termos percentuais, dos 67 artigos investigados, 76\% (51 artigos) constam com 1 entre 5 autores. Do total de artigos, 4 não foram feitos em coautoria, isto é, $6 \%$ da amostra foram publicados individualmente.

Quanto à filiação dos autores, diversas foram as instituições às quais estão eles vinculados. Entre universidades e centro de pesquisa, as academias do Estado de Minas Gerais constam o maior número de artigos publicados sobre certificação florestal, totalizando 22 documentos pelas Universidade Federal de 
Viçosa (UFV) e Universidade Estadual de Minas Gerais (UFMG). O Estado de São Paulo apresentou o total de 17 documentos que estão divididos entre a Universidade de São Paulo (USP), a Universidade Estadual de Campinas (UNICAMP) e a Universidade Estadual Paulista (UNESP). O Estado do Rio Grande do Sul, representado pela Universidade Federal do Pampa (UNIPAMPA) conta com 5 documentos, seguido da instituição da Empresa Brasileira de Pesquisa Agropecuária (EMBRAPA) com 4 documentos.

Dentre as universidades citadas, as com maior número de publicações são a federal de Minas Gerais, representando 19,4\% dos artigos publicados (13 documentos), a Universidade de São Paulo com 14,9\% (10 documentos) e a federal de Minas Gerais com 13,4\% (9 documentos), podendo ser observado no Gráfico 3.

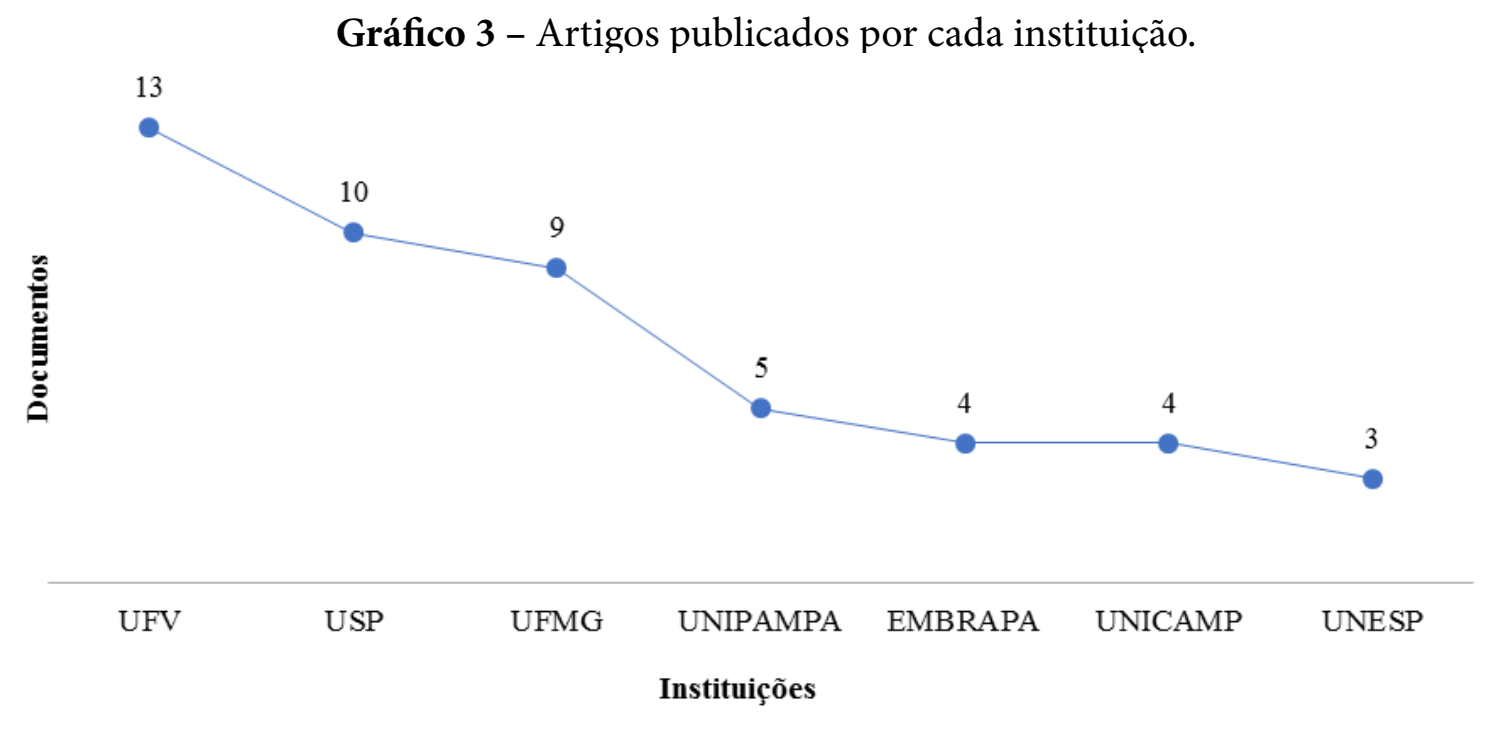

Fonte: Dados da pesquisa (2019).

Ribeiro e Côrrea (2013) citados por Freitas e Paiva (2018) discorrem sobre a importância do pesquisador para a Instituição de Ensino Superior (IES), pois é parte fundamental no desenvolvimento de pesquisas que influenciam e impactam no crescimento de suas filiações.

Publicações por periódicos e número de citações

Os documentos foram publicados em 45 periódicos diferentes, nacionais e internacionais, sendo o periódico Revista Árvore com 10,45\% de todas as publicações acerca da certificação florestal investigados. O periódico tem como objetivo disseminar a produção científica na área de Ciência Florestal. O segundo periódico com maior número de publicações foi o internacional Forest Ecology and Management, que tem como foco a publicação de artigos voltados para o manejo florestal considerando estudos ecológicos e principalmente a conservação de florestas naturais. A Tabela 1 mostra os periódicos com mais publicações sobre certificação florestal investigados nesta pesquisa.

Quanto às citações de alguns periódicos, os artigos do periódico Forest Ecology and Management tiveram 292 citações, seguidos do periódico Austral Ecology com 143 citações, Journal of Applied Ecology com 78 citações, Frontiers in Ecology and the Environment com 58 citações, Ecological Modelling com 48, Forest Policy and Economics com 41 citações, PloS ONE com 38 citações e Revista Árvore com 27 citações. Os periódicos Bioscience Journal, Desenvolvimento e Meio Ambiente, Mondes en Developpement e Revista de Economia e Sociologia Rural, não tiveram nenhuma citação.

Além disso, foram observados os artigos individualmente com maior número de citações, conforme apresenta a Tabela 2 . 
Tabela 1 - Periódicos com publicações de brasileiros sobre certificação florestal.

\begin{tabular}{|c|c|}
\hline Periódico & Publicações \\
\hline Revista Árvore & 7 \\
\hline Forest Ecology and Management & 5 \\
\hline Forest Policy and Economics & 5 \\
\hline Floresta & 3 \\
\hline Floresta e Ambiente & 3 \\
\hline Austral Ecology & 2 \\
\hline International Forestry Review & 2 \\
\hline Journal of Cleaner Production & 2 \\
\hline Society and Natural Resources & 2 \\
\hline Ambiente e Sociedade & 1 \\
\hline Bioscience Journal & 1 \\
\hline Biotropica & 1 \\
\hline Boletimdo Museu Paraense Emilio Goeldi:Ciencias Humanas & 1 \\
\hline Caderno CRH & 1 \\
\hline Cerne & 1 \\
\hline Computers and Electronics in Agriculture & 1 \\
\hline Conservation Letters & 1 \\
\hline Desenvolvimento e Meio Ambiente & 1 \\
\hline Ecological Applications & 1 \\
\hline Ecological Modelling & 1 \\
\hline Ecology and Society & 1 \\
\hline Ecosystem Services & 1 \\
\hline Engenharia Agricola & 1 \\
\hline Environmental Conservation & 1 \\
\hline Environmental Science and Pollution Research & 1 \\
\hline Estudos Avançados & 1 \\
\hline Forests Trees and Livelihoods & 1 \\
\hline Frontiers in Ecology and the Environment & 1 \\
\hline GCB Bioenergy & 1 \\
\hline Global Change Biology & 1 \\
\hline Global Environmental Change & 1 \\
\hline Horizontes Antropologicos & 1 \\
\hline IDS Bulletin & 1 \\
\hline $\begin{array}{l}\text { International Journal of Sustainable Development and World Ecol- } \\
\text { ogy }\end{array}$ & 1 \\
\hline Journal of Applied Ecology & 1 \\
\hline Journal of Forestry & 1 \\
\hline Mondes en Developpement & 1 \\
\hline ORYX & 1 \\
\hline Outlooks on Pest Management & 1 \\
\hline PLoS ONE & 1 \\
\hline
\end{tabular}


Tabela 1 - Periódicos com publicações de brasileiros sobre certificação florestal (cont.).

\begin{tabular}{lc} 
Revista Brasileira de Gestao e Desenvolvimento Regional & 1 \\
Revista de Economia e Sociologia Rural & 1 \\
Sociedade e Estado & 1 \\
Sustainable Cities and Society & 1 \\
Theory, Culture \& Society & 1 \\
\hline Total & 67 \\
\hline
\end{tabular}

Fonte: Elaborado pelos autores.

Tabela 2 - Artigos com maior número de citações.

\begin{tabular}{|c|c|c|c|}
\hline Autor & Título & Periódico & Citações \\
\hline $\begin{array}{l}\text { Rodrigues R.R. et al. } \\
\text { (2011) }\end{array}$ & $\begin{array}{l}\text { Large-scale ecological restoration of high-di- } \\
\text { versity tropical forests in SE Brazil }\end{array}$ & $\begin{array}{l}\text { Forest Ecology and } \\
\text { Management }\end{array}$ & 166 \\
\hline $\begin{array}{l}\text { Simberloff D. et al. } \\
(2010)\end{array}$ & $\begin{array}{l}\text { Spread and impact of introduced conifers in } \\
\text { South America: Lessons from other southern } \\
\text { hemisphere regions }\end{array}$ & Austral Ecology & 143 \\
\hline $\begin{array}{l}\text { Read J.M. et al. } \\
(2003)\end{array}$ & $\begin{array}{l}\text { Application of merged } 1-\mathrm{m} \text { and } 4-\mathrm{m} \text { resolution } \\
\text { satellite data to research and management in } \\
\text { tropical forests }\end{array}$ & $\begin{array}{l}\text { Journal of Applied } \\
\text { Ecology }\end{array}$ & 78 \\
\hline $\begin{array}{l}\text { Latawiec A.E. et al. } \\
\text { (2015) }\end{array}$ & $\begin{array}{l}\text { Creating space for large-scale restoration in } \\
\text { tropical agricultural landscapes }\end{array}$ & $\begin{array}{l}\text { Frontiers in Ecology } \\
\text { and the Environment }\end{array}$ & 58 \\
\hline $\begin{array}{l}\text { Feldpausch T.R. et al. } \\
\text { (2005) }\end{array}$ & $\begin{array}{l}\text { When big trees fall: Damage and carbon export } \\
\text { by reduced impact logging in southern Ama- } \\
\text { zonia }\end{array}$ & $\begin{array}{l}\text { Forest Ecology and } \\
\text { Management }\end{array}$ & 58 \\
\hline $\begin{array}{l}\text { Van Gardingen P.R. } \\
\text { et al. (2006) }\end{array}$ & $\begin{array}{l}\text { Evaluation of yield regulation options for pri- } \\
\text { mary forest in Tapajós National Forest, Brazil }\end{array}$ & $\begin{array}{l}\text { Forest Ecology and } \\
\text { Management }\end{array}$ & 56 \\
\hline $\begin{array}{l}\text { Phillips P.D. et al. } \\
\text { (2004) }\end{array}$ & $\begin{array}{l}\text { An individual-based spatially explicit simu- } \\
\text { lation model for strategic forest management } \\
\text { planning in the eastern Amazon }\end{array}$ & Ecological Modelling & 48 \\
\hline $\begin{array}{l}\text { Soares-Filho B. et al. } \\
\text { (2016) }\end{array}$ & Brazil's market for trading forest certificates & PloS ONE & 38 \\
\hline $\begin{array}{l}\text { Pinto L.F.G., McDer- } \\
\text { mott C. (2013) }\end{array}$ & $\begin{array}{l}\text { Equity and forest certification - A case study in } \\
\text { Brazil }\end{array}$ & $\begin{array}{l}\text { Forest Policy and Eco- } \\
\text { nomics }\end{array}$ & 25 \\
\hline $\begin{array}{l}\text { Homma A.K.O. } \\
(2012)\end{array}$ & $\begin{array}{l}\text { Extrativismo vegetal ou plantio: Qual a opção } \\
\text { para a Amazônia? }\end{array}$ & Estudos Avançados & 21 \\
\hline
\end{tabular}

Fonte: Elaborado pelos autores.

O artigo mais citado foi o do Rodrigues et al. (2011), "Large-scale ecological restoration of high-diversity tropical forests in SE Brazil”, com 166 citações. Os autores Freitas e Paiva (2018) apontam a importância das citações de um artigo, pois estas indicam o impacto que o mesmo causa dentro de sua área de conhecimento, corroborando com Moraes et al. (2015), que afirmam que as citações medem o impacto e visibilidade não só dos autores, como das instituições a qual pertencem.

Vanz (2003) citado por Araújo e Alvarenga (2011) destaca que uma rede de citação ou cocitação é um indicador válido e confiável, que permite evidenciar quais os pensamentos se destacam dentro de um 
grupo ou uma escola, e que um dos parâmetros usados para isso é a quantidade de vezes que um trabalho é citado, pois quanto maior essa quantidade, maior a possibilidade de relação entre autores citados.

\section{FrequênCIA dAS PALAVRAS nOS TEXTOS}

Nesta parte do estudo buscou-se extrair os termos mais frequentes nos textos encontrados, tanto contidos no resumo quanto no título dos trabalhos, totalizando assim 2.304 termos. Para redução e melhor interpretação no mapa, estipulou-se como critério mínimo de ocorrência, ao menos cinco termos, constatando assim 81 termos, segmentado em 3 clusters como mostra a Figura 3.

Figura 3 - Termos mais relevantes encontrados nos textos sobre certificação florestal.

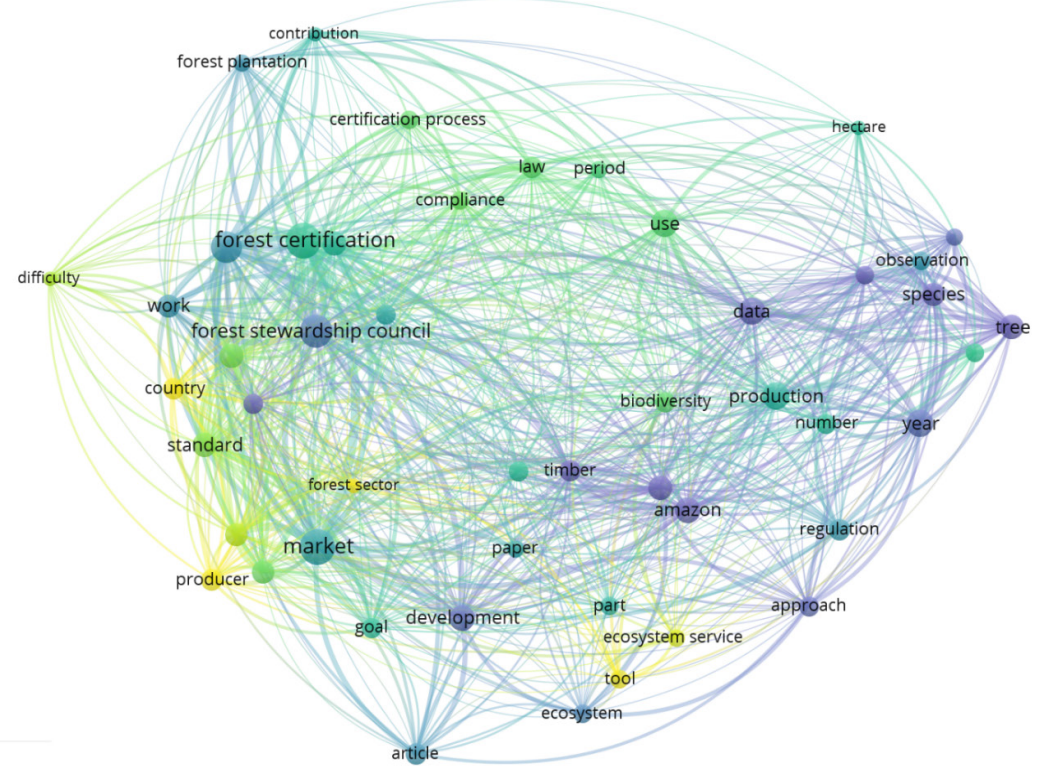

Os termos mais evidenciados na pesquisa foram forest certification com 22 ocorrências, market com 21 ocorrências, forest stewardship council com 19 ocorrências e fsc com 17 ocorrências.

Optou-se por construir uma rede co-ocorrência de palavras-chave, possibilitando assim identificar a frequência, ocorrência e as relações entre determinadas citações, bem como feito no estudo de Freitas e Paiva (2018). Silva et al. (2018) identificam as palavras-chave como forma de desenvolvimento na expansão de um campo de conhecimento, pois as mesmas permitem facilitar a busca e o acesso a outras produções.

Levando em consideração as palavras-chaves encontradas, a Figura 4 aponta possíveis temas para pesquisas posteriores acerca da certificação florestal, bem como dimensiona a ideia sobre o assunto, deixando mais claro os termos passíveis de pesquisa e aprofundamento antes da elaboração de novos estudos.

Figura 4 - Co-ocorrência de palavras-chave. 


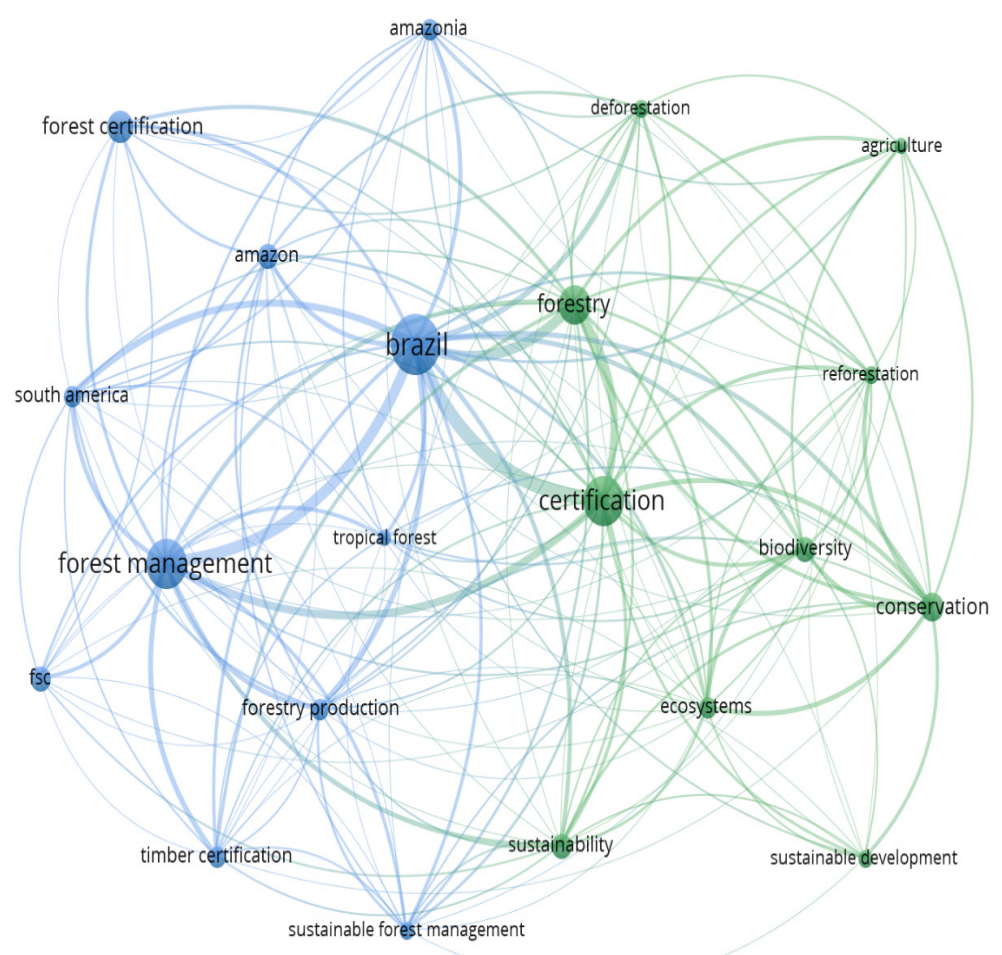

Fonte: Dados da pesquisa (2019).

A rede de co-ocorrência de palavras-chave apresentou 538 palavras-chave, porém com a limitação da ocorrência em apenas cinco, identificou 21 nós divididos em apenas dois clusters. Os clusters estão identificados em (1) azul e (2) verde; isso permite perceber as temáticas abordadas pelos artigos em cada um dos grupos. O primeiro cluster (1) teve palavras-chave como forest management, brazil e forest certification. As menos recorrentes dentro deste grupo foram tropical forest, timber certification e south america.

No segundo cluster (2), as palavras de maior ocorrência são: certification, forestry, conservation e sustainability. Em contramão, aparecem dois termos menos recorrentes, agriculture e reforestation, termos estes que a certo modo se relacionam com o desmatar e reflorestar. Tiveram artigos que abordaram o uso de terras para produção de alimentos, no entanto as pesquisas se atentaram mais as conformidades e os impactos da certificação florestal sob aquela propriedade. As palavras aqui encontradas estão de acordo com o tema abordado pela pesquisa.

\section{CONSTATAÇÕES SOBRE OS ARTIGOS INVESTIGADOS}

Em suma, os artigos sobre certificação florestal encontrados na base de dados da Scopus buscaram abordar a certificação como ferramenta para mercado competitivo e preservação das florestas. A análise qualitativa dos artigos dos 3 periódicos com maior número de publicações acerca do tema, visto na Tabela 1 , buscou apresentar os principais resultados e contribuições.

O estudo de Basso et al. (2011) retratou a importância da certificação florestal levando em consideração o crescente desmatamento de florestas no país, e objetivou apresentar a contribuição dessa ferramenta quando em conformidade com a legislação ambiental e florestal das unidades de manejo das florestas plantadas. O estudo contou com o levantamento de dados mediante relatórios públicos de empresas 
certificadas entre os anos de 1996 e 2007, com enfoque no Princípio 1 da certificação FSC, apontando como resultado que o maior problema para as empresas estava relacionado com Áreas de Preservação Permanente (APP) e Reserva Legal (RL). Os autores concluíram que a certificação florestal estipulando um prazo para adequação das não conformidades, contribui com o cumprimento da legislação nas unidades de manejo das empresas, o que consequentemente contribui com a exploração de florestas e processo de produção.

Alves et al. (2011) abordando os padrões de certificação FSC e CERFLOR, consultaram os relatórios públicos das unidades de manejo para florestas plantadas e nativas, objetivando analisar a contribuição dos dois padrões selecionados pelas empresas nos estados brasileiros. Para os autores, a conclusão de que o sistema de certificação florestal não influencia de maneira relevante, pois o cumprimento das empresas perante à legislação continua sendo exigido independe do sistema escolhido.

No estudo dos mesmos autores, Alves et al. (2009), o objetivo a respeito da certificação florestal foi compreender a visão das indústrias moveleiras sobre aderir ou não ao sistema FSC. Constaram assim que naquela época, para as empresas não era viável certificar seus produtos quando se tratava do mercado interno, diferentemente ao se pensar para o mercado de exportação, onde os clientes exigiam muito mais por produtos com selo verde. Semelhante ao estudo de Jacovine et al. (2006), que tinha como objetivo avaliar o processo da certificação florestal nas indústrias moveleiras do país. Os autores desse estudo puderam concluir que para as empresas, o conhecimento de certificação florestal se resumia somente ao sistema FSC, não tendo nenhuma experiência com outro tipo de certificação, e que as empresas questionavam o tempo gasto com a normalização das não conformidades frente à visita da consultoria.

Dentre os 17 artigos analisados qualitativamente, alguns estudos buscaram abordar o manejo das florestas brasileiras visando considerar sua ecologia e os cuidados necessários para preservação. Na pesquisa de Rodrigues et al. (2011) o objetivo era apresentar áreas de fazendas que continham pouca ou nenhuma estrutura florestal protegida, propondo métodos de restauração e preservação das respectivas áreas com grande diversidade de espécies nativas.

Em estudo com enfoque socioambiental, Hardt et al. (2015) apresentaram a importância da certificação para as comunidades e a conservação de áreas verdes. Os autores investigaram fazendas brasileiras em termos de desmatamento, proteção e regeneração das florestas, conectando o aspecto paisagístico. Concluíram que das fazendas investigadas, àquelas com certificação apresentaram a grosso modo uma contribuição maior para as áreas ao redor, contribuindo na preservação de áreas de lazer e áreas agrícolas.

Piketty e Drigo (2018) analisando o escopo das auditorias do sistema FSC, conhecido como o mais amplamente aceito mundialmente, constataram que a certificação por esse sistema não deixa espaço para subjetividade, porém para as autoras, o sistema FSC de certificação florestal possui alguns critérios considerados amplos, necessitando de indicadores mais diretos. Rafael et al. (2018) explorando os principais desafios das empresas para certificarem com o sistema FSC, consideraram que as não conformidades das empresas que mais tiveram percentuais relevantes estavam relacionadas ao "impacto ambiental", "monitoramento e avaliação das atividades" e "relação com comunidades e direitos do trabalhador". Os autores apresentaram a observação de que estudos sobre o tema, geralmente apontam os princípios 4 e 6 do FSC como os de maiores não conformidades encontradas em empresas estudadas.

Em suma, as recomendações dos artigos, de forma explicita ou não, mostram a necessidade de algumas visões diferentes sobre estudos de certificação florestal. Diante do observado, o contexto social da certificação tem se mostrado pouco explorado quando comparado ao econômico e ambiental.

\section{Conclusões}

A investigação da produção científica internacional acerca da certificação florestal por autores brasileiros mostrou um campo de exploração muito pequeno comparado a autores internacionais. 
A pesquisa apontou que os autores se encontram bastante concentrados em instituições nos Estados de São Paulo, Minas Gerais, e parte no Rio Grande do Sul, dado a vasta extensão territorial do país e com biomas tão diversos. Os autores com maior número de publicações acerca do tema, trabalhando muito em coautoria, se concentram na Universidade Federal de Viçosa, Estado de Minas Gerais.

É notório o crescente desenvolvimento de estudos sobre certificação, podendo ser percebido na análise descritiva ao longo dos anos. A perspectiva dos estudos está bastante voltada para questões econômicas e ambientais das empresas que procuram algum sistema de certificação; poucos foram os trabalhos visando o âmbito social do impacto que certificar uma floresta pode causar nas comunidades. Outro ponto percebido foi que muitos autores têm realizado estudos em conjunto com autores internacionais, mas em território brasileiro, o que pode indicar a importância das florestas nacionais diante dos olhos do mundo.

Por se tratar de uma ferramenta aplicada em empresas como forma de competitividade e para cumprir com a legislação do país, os estudos investigados estão em grande parte limitados ao ponto de vista das empresas de base florestal ou agrícola.

O presente estudo apresenta suas próprias limitações sendo que o número de periódicos pode ser considerado pequeno, considerando o tema como bastante estudado por autores internacionais; as palavras-chave foram delimitadas em função do tema principal, não sendo pesquisada nenhuma outra além de "forest certification"; somente uma base de dados foi utilizada (Scopus) para coletar as informações necessárias. Sugere-se o enfoque em estudos que visem a percepção do consumidor de produtos certificados, bem como a busca por outros bancos de dados.

\section{REFERÊNCIAS}

ALVES, R.R.; JACOVINE, L.A.G.; SILVA, M.L. da. Plantações florestais e a proteção de florestas nativas em unidades de manejo certificadas no Brasil. Revista Árvore, v.35, n.4, p.859-866, 2011. http://dx.doi.org/10.1590/ S0100-67622011000500011. Acesso em: 11 set. 2019.

ALVES, R.R.; JACOVINE, L.A.G.; SILVA, M.L.de.; VALVERDE, S.R.; SILVA, J. de C.; NARDELLI, A.M.B. Certificação florestal e o mercado moveleiro nacional. Revista Árvore, v.33, n.3, p.583-589, 2009. http://dx.doi. org/10.1590/S0100-67622009000300020. Acesso em: 11 set. 2019.

BASSO, V.M.; JACOVINE, L.A.G.; ALVES, R.R.; VALVERDE, S.R.; SILVA, F.L. da; BRIANEZI, D. Avaliação da influência da certificação florestal no cumprimento da legislação ambiental em plantações florestais. Revista Árvore, v.35, n.4, p.835-844, 2011. http://dx.doi.org/10.1590/S0100-67622009000300020. Acesso em: 11 set. 2019.

CARNEIRO, M.S. Da certificação para as concessões florestais: organizações não governamentais, empresas e a construção de um novo quadro institucional para o desenvolvimento da exploração florestal na Amazônia brasileira. Boletim do Museu Paraense Emílio Goeldi, v.6, n.3, p.525-541, 2011. Disponível em: http://www.scielo.br/ pdf/bgoeldi/v6n3/04. Acesso em: 11 set. 2019.

FREITAS, A.R.P.; PAIVA, L.E.B. Revisão da produção científica internacional de brasileiros acerca das mudanças climáticas. Revista de Gestão Social e Ambiental. São Paulo, v.12, n.3, p.95-113, 2018. https://doi.org/10.24857/ rgsa.v12i3.1615. Acesso em: 25 set. 2019.

HARDT, E.; BORGOMEO, E.; SANTOS, R.F. dos; PINTO, L.F.G.; METZGER, J.P.; SPAROVEK, G. Does certification improve biodiversity conservation in Brazilian coffee farms? Forest Ecology and Management, v.357, p.181-194, 2015. http://dx.doi.org/10.1016/j.foreco.2015.08.021. Acesso em: 16 set. 2019.

JACOVINE, L.A.G.; ALVES, R.R.; VALVERDE, S.R.; SILVA, M.L. da; NARDELLI, A.M.B.; SOUZA, A.P. de. Pro- 
Freire et al.

cesso da implementação da certificação florestal nas empresas moveleiras nacionais. Revista Árvore, v.30, n.6, p.961-968, 2006. http://dx.doi.org/10.1590/S0100-67622006000600011. Acesso em: 11 set. 2019.

LACERDA, R.T.O.; ENSSLIN, L.; ENSSLIN, S.R. Uma análise bibliométrica da literatura sobre estratégia e avaliação de desempenho. Revista Gestão e Produção. São Carlos, v.19, n.1, p.59-78, 2012. http://dx.doi.org/10.1590/ S0104-530X2012000100005. Acesso em: 02 out. 2019.

LEITE, M.V.S.; ANTUNES, A.F.F.; CABACINHA, C.D.; ASSIS, A.L.; GAMA, A.T. da; SALES, N. de L.P. Compliance with Environmental and Social Legislation in Certified Forestry Companies. Revista Floresta e Ambiente. Rio de Janeiro, v.25, n.1, 11 p., 2018. http://dx.doi.org/10.1590/2179-8087.010015. Acesso em: 02 out. 2019.

MAIA, M.F.; CAREGNATO, S.E. Co-autoria como indicador de redes de colaboração científica. Perspectivas em Ciência da Informação, v.13, n.2, p.18-31, 2008. http://dx.doi.org/10.1590/S1413-99362008000200003. Acesso em: 25 set. 2019.

MENA-CHALCO, J.P.; DIGIAMPIETRI, L.A.; CESAR-JUNIOR, R.M. Caracterizando as redes de coautoria de currículos Lattes. Journal of the Brazilian Computer Society, 2012. http://dx.doi.org/10.13140/ RG.2.1.2849.1364. Acesso em: 20 set. 2019.

MORAES, M.; FURTADO, R.L.; TOMAÉL, M.I. Redes de citação: estudo de rede de pesquisadores a partir da competência em informação. Revista Em Questão, Porto Alegre, v.21, n.2, p.181-202, 2015. https://doi. org/10.19132/1808-5245212.181-202. Acesso em: 27 set. 2019.

MOURA, A.M.M., In: DA SILVA, A.P.M.; MARQUES, H.R.; SAMBUICHI, R.H.R. (Org.) Contribuição da certificação de florestas para o cumprimento da legislação florestal no Brasil. Mudanças no Código Florestal Brasileiro: desafios para a implementação da nova lei. Rio de Janeiro: IPEA, 2016, p. 359. Disponível em: http://repositorio.ipea.gov.br/bitstream/11058/9233/1/Contribui\%C3\%A7\%C3\%A3o\%20da\%20certifica\%C3\%A7\%C3\%A3o. pdf. Acesso: 21 set. 2019.

PAIVA, S.N.; SILVA, D.A. da; OSHIRO, C.R.; HOSOKAWA, R.T.; ROCHADELLI, R. A certificação florestal pelo FSC: um estudo de caso. Revista Floresta. Curitiba, v.45, n.2, p.213-222, 2015. https://doi.org/10.5380/rf. v45i2.30055. Acesso em: 27 set. 2019.

PIKETTY, M.; DRIGO, I.G. Shaping the implementation of the FSC standard: the case of auditors in Brazil. Forest Policy and Economics, v. 90, p.160-166, 2018. https://doi.org/10.1016/j.forpol.2018.02.009. Acesso em: 17 set. 2019.

PINTO, L.F.G.; MCDERMOTT, C. Equity and forest certification - A case study in Brazil. Forest Policy and Economics, v.30, p.23-39, 2013. http://dx.doi.org/10.1016/j.forpol.2013.03.002. Acesso em: 23 set. 2019.

RAFAEL, G. C.; FONSECA; A.; JACOVINE, L.A.G. Non-conformities to the Forest Stewardship Council (FSC) standards: Empirical evidence and implications for policy-making in Brazil. Forest Policy and Economics, v. 88, p.59-69, 2018. https://doi.org/10.1016/j.forpol.2017.12.013. Acesso em: 11 set. 2019.

RODRIGUES, R.R.; GANDOLFI, S.; NAVE, A.G.; ARONSON, J.; BARRETO, T.E.; VIDAL, C.Y.; BRANCALION, P.H.S. Large-scale Ecological restoration of high-diversity tropical forests in SE Brazil. Forest Ecology and Management, v.261, n.10, p.1605-1613, 2011. https://doi.org/10.1016/j.foreco.2010.07.005. Acesso em: 02 out. 2019.

SAMPAIO, R.B.; SACERDOTE, H.C. de S.; FONSECA, B. de P.F.; FERNANDES, J.H.C. A colaboração científica 
na pesquisa sobre coautoria: um método baseado na análise de redes. Perspectiva em Ciência da Informação, v.20, n.4, p.79-92, 2015. http://dx.doi.org/10.1590/1981-5344/2447. Acesso em: 20 set. 2019.

SANTOS, G.C. Análise bibliométrica dos artigos publicados como estudos de bibliométrico na história do Congresso Brasileiro de Custos. Pensar Contábil, Rio de Janeiro, v.17, n.64, p.4-13, 2015. http://www.spell.org.br/ documentos/ver/37276/analise-bibliometrica-dos-artigos-publicados-como-estudos-bibliometricos-na-historia-do-congresso-brasileiro-de-custos-/i/pt-br. Acesso em: 25 set. 2019.

SANTOS, R.N.M. Produção científica: Por que medir? O que medir? Revista Eletrônica de Biblioteconomia e Ciência da Informação. Campinas, v.1, n.1, p.22-38, 2003. https://doi.org/10.20396/rdbci.v1i1.2087. Acesso em: 20 set. 2019.

SILVA, F.M.; SOBRAL, N.V.; SANTANA, G.A.; CRUZ, T.L. Mapeamento da produção científica brasileira sobre acesso aberto: 2001 a 2011. Encontros Bibliográficos, Revista Eletrônica de Biblioteconomia e Ciência da Informação. Campinas, v.17, n.2, p.19-35, 2012. http://dx.doi.org/10.5007/1518-2924.2012v17nesp2p19. Acesso em: 23 set. 2019.

SILVA, J.T.M; ABLANEDO-ROSAS, J.H.; ROSSETTO, D.E. A longitudinal literature network review of contributions made to the academy over the past 55 years of the IJPR. International Journal of Production Research, p.1-27, 2018. https://doi.org/10.1080/00207543.2018.1484953. Acesso em: 25 set. 2019.

SILVA, M.R.; HAYASHI, C.R.M.; HAYASHI, M.C.P.I. Análise bibliométrica e cientométrica: desafios para especialistas que atuam no campo. InCID: Revista de Ciência da Informação e Documentação. Ribeirão Preto, v. 2, n.1, p.110-129, 2011. https://doi.org/10.11606/issn.2178-2075.v2i1p110-129. Acesso em: 25 set. 2019.

TAVEIRA, L.D.B.; MEDEIROS, A.W.; CAMARA, R.P. de B.; MARTINS, J.D.M. Uma análise bibliométrica dos artigos científicos em perícia contábil publicados entre os anos de 1999 a 2012. Revista de Contabilidade do Mestrado em Ciências Contábeis da UERJ (online). Rio de Janeiro, v.18, n.2, p.49-64, 2013. https://doi. org/10.12979/7264. Acesso em: 25 set. 2019.

VAN ECK, N.J.; WALTMAN, L. Software survey: VOSviewer, a computer program for bibliometric mapping. Scientometrics, v.84, n.2, p.523-538, 2010. https://doi.org/10.1007/s11192-009-0146-3. Acesso em: 25 set. 2019. 